\title{
Assessing Debt Sustainability in a Stochastic Environment: 200 Years of Dutch Debt and Deficit Management
}

\author{
Sweder van Wijnbergen • Alexander France
}

Published online: 4 April 2012

(C) The Author(s) 2012. This article is published with open access at Springerlink.com

\begin{abstract}
When debt levels approach critical levels, tax payers may revolt against the associated debt service burden. Funding problems may arise in capital markets when lenders anticipate such revolts and refuse to participate in debt auctions. We provide a stochastic framework to assess whether such problems may arise and argue that the key to fiscal sustainability in a stochastic environment is a feedback rule from debt level shocks back to corresponding adjustments in the primary surplus. We show that such feedback rules narrow future distributions of debt-output ratios and so reduce crisis probabilities. We apply the methodology to Dutch debt and deficit data spanning two centuries. Our results strongly argue for the incorporation of rules stipulating tightening fiscal policy whenever debt stocks exceed previously agreed upon targets (like in the original Eurozone Stability pact).
\end{abstract}

Keywords Deficits $\cdot$ Debt sustainability $\cdot$ Fiscal rules

JEL Classification E62 $\cdot \mathrm{H} 62 \cdot \mathrm{H} 63 \cdot \mathrm{H} 68$

Electronic supplementary material The online version of this article (doi:10.1007/s10645-012-9188-7) contains supplementary material, which is available to authorized users.

S. van Wijnbergen $(\varangle)$

University of Amsterdam and Tinbergen Institute, Amsterdam,

The Netherlands

e-mail: s.j.g.vanwijnbergen@uva.nl

A. France

University of Amsterdam, Amsterdam, The Netherlands 


\section{Introduction}

The recent crises in the Euro area have highlighted the importance of fiscal sustainability, loosely defined as the likelihood that budgetary policies can be sustained without major policy changes and without incurring runaway debt levels. Unsustainable policies by this definition signal major policy change (Davig et al. 2011) or binding capital market participation constraints (Bohn 2007), i.e. inability to place further government debt.

Going from this intuitive but loose definition to a quantitative assessment of sustainability has proven to be a difficult step, spawning a large but diverse literature. The theory is clear: if the debt and deficit processes together satisfy the Intertemporal Budget Constraint (ITBC) of the Government, i.e. the discounted value of future primary surpluses equals or exceeds initial debt, policies are deemed sustainable and can be pursued without expecting capital market funding problems. Equivalently, the debt process needs to satisfy a Terminal Value Condition (TVC) stating that the discounted value of future debt stocks should limit to zero as time goes to infinity, i.e. the debt should eventually grow at less than the rate of interest. ${ }^{1}$ In a deterministic world, that is where it ends. In a stochastic environment, the ITBC and TVC have similar equivalents, but expressed in expected value terms.

But the translation of these stochastic equivalents into quantitative assessments of the sustainability of actual ongoing processes is complicated. In the academic literature much attention has been paid to the analysis of the stochastic characteristics of historical debt, revenue and expenditure processes. There is a substantial literature assuming the necessity for debt/deficit processes to pass rejection of unit root tests, or for expenditure and revenue processes to be difference-stationary, to be considered sustainable. However in a powerful recent paper, Bohn (2007) has demonstrated that difference stationarity of any finite order is consistent with satisfaction of the Intertemporal Budget Constraint (ITBC) and suggests alternative approaches focusing on the presence of Error Correction Mechanisms in the debt/deficit processes. Is the country under consideration sufficiently responsive to rising debt levels?

There is also a more economic approach to assessing fiscal sustainability, focusing less on the statistical properties of the time series for debt/deficits. That literature assumes there are fiscal limits (Davig et al. 2011; Schabert and van Wijnbergen 2006, 2010) and considers prospective tax levels beyond those limits as signals of policy change and in that sense as indicators of unsustainability. In a related approach, Reinhart et al. (2003) have introduced the concept of debt tolerance, levels of debt above which placing of debt in capital markets becomes more difficult and more expensive, as default expectations start to rise in debt levels. Typically the debt tolerance limits are expressed as limits on debt/GDP ratios, with an appeal on maximum sustainable ratios of debt service to GDP, in a manner similar to the fiscal limits of Davig et al. (2011) and Schabert and van Wijnbergen (2006, 2010).

In this paper we apply the Bohn (2007) approach to a long Dutch time series on debt and deficits, running from Napoleonic times to the present. We show that Dutch

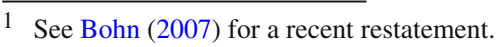


fiscal policy has always been sufficiently responsive to rising debt levels and conclude that the ITBC has not been violated. We also test whether this responsiveness has increased or decreased in recent times; has the introduction of the Euro and the associated stability pact led to more emphasis on restrictive budgetary policies?

We finally introduce a new measure of sustainability based on the second "fiscal limits" approach, but applied in a stochastic environment: the probability that the debt output ratio at any time will exceed debt tolerance levels. We furthermore show how the two approaches interact: we demonstrate that higher feedback coefficients significantly narrow fan charts of debt/output ratios, i.e. reduce variance, and so reduce the probability of transgressing debt tolerance limits, if at least the expected time path stays under this limit to begin with.

\section{Theoretical Framework}

We start from the within period budget constraint, more an accounting identity:

$$
b_{t}=d_{t}+\left(1+r_{t}\right) b_{t-1}
$$

All variables (debt $b_{t}$, the primary deficit $d_{t}$ and the interest rate $r$ ) should be defined in a consistent manner, i.e. if $b_{t}$ and $d_{t}$ are nominal variables, $r$ is the nominal interest rate, if they are real variables $r$ is the real interest rate and if they are expressed as ratios to GDP $r$ is the growth-adjusted real interest rate. The formulas in this section assume a constant " $r$ "; extension to a time varying " $r$ " is trivial but cumbersome notationwise. Trehan and Walsh (1991) establish that the ITBC is satisfied if $d_{t}$ and $b_{t}$ are cointegrated and $\left(d_{t}-\lambda b_{t-1}\right) \sim I(0)$ for some $\lambda \in[0,1+r]$. Note that if $d_{t}$ and $b_{t-1}$ are $I(1)$, the cointegration assumption implies that there exists a cointegration vector (in this two dimensional example a cointegration constant) $\alpha$ for which the following holds:

$$
d_{t}+\alpha b_{t-1}=\varepsilon_{t} \sim I(0)
$$

where the only property of $\varepsilon_{t}$ that is defined now is that it is $I(0)$. Additional characteristics of $\varepsilon_{t}$ will be assumed below but are not yet relevant. (1) and (2) together imply:

$$
b_{t}=(1+r-\alpha) b_{t-1}+\varepsilon_{t}
$$

This links the sustainability literature to the literature on fiscal reaction functions, as pointed out by Bohn (2007):

- reaction functions with $\alpha>r$ imply stationary debt and deficits;

- reaction functions with $0<\alpha<r$ imply explosive paths for $b$ and $d$, but growing slowly enough to remain within the ITBC.

- reaction functions with $\alpha<0$ imply unsustainable processes.

The proposed new sustainability measure is based on the concept of debt intolerance introduced by Reinhart et al. (2003). They define the tolerance limit of a country as the level of debt (defined as a ratio to GDP) above which placing further debt in capital 
markets becomes problematic. If the "tolerance limit" equals $b_{t+\tau}^{\text {TOL.LIM }}$, we define a time series $\left\{P_{t+\tau}\right\}$ where $\left\{P_{t+\tau}\right\}$ equals the probability that at time $t+\tau$ the debt output ratio exceeds the debt tolerance limit of that year: $P_{t+\tau}=\operatorname{Prob}\left(b_{t+\tau}>b_{t+\tau}^{\text {TOL.LIM }}\right)$. To translate such a time series into a single measure evaluated at time $t$ would require a full model of what is likely to happen once debt exceeds the debt tolerance limit at any point in time. To avoid the model specificity that such a measure would introduce, we restrict ourselves to the calculation of $\left\{P_{t+\tau}\right\}$ and an empirical assessment of whether that series is tending to zero with the passage of time.

Consider next the variance of projected future debtlevels under a feedback rule as proposed by Bohn (2007). We collapse all possible stochastic shocks into a single shock to the primary deficit $\mathrm{d}_{t}$ :

$$
\begin{aligned}
\text { (i) } b_{t} & =d_{t}+(1+r) b_{t-1} \\
\text { (ii) } d_{t} & =\bar{d}_{t}+\varepsilon_{t} \\
(\text { i }),(\text { ii }) & \Rightarrow(\text { iii }) b_{t}=\bar{d}_{t}+\varepsilon_{t}+(1+r) b_{t-1}
\end{aligned}
$$

(4iii) is obtained by inserting (4ii) into $(4 i), \bar{d}_{t}$ is the non-stochastic part of the primary deficit process. Define $b_{t}^{\tau}$ as the (stochastic) projection of $b$, constructed at time $t$, for $\tau$ periods ahead. $\varepsilon_{t}$, the shocks to $\boldsymbol{d}_{t}$, are i.i.d. with constant variance $\sigma$, so the variance of this projection equals:

$$
\begin{aligned}
\operatorname{var}\left(b_{t}^{\tau}\right) & =\operatorname{var}\left(\sum_{t^{\prime}=1}^{t /=\tau} \varepsilon_{t^{\prime}}(1+r)^{t^{\prime}-1}\right) \\
& =\sigma^{2} \sum_{t \prime=1}^{t^{\prime}=\tau}\left((1+r)^{2}\right)^{t^{\prime}-1} \\
& =\sigma^{2} \frac{(1+r)^{2 \tau}-1}{(1+r)^{2}-1}
\end{aligned}
$$

where to avoid tedious notation and without loss of generality we assume a constant rate of interest $r$. Clearly when $\tau \rightarrow \infty$ then $\operatorname{var}\left(b_{t}^{\tau}\right) \rightarrow \infty$. So if the Government does not take any action, the variance of debt grows infinitely large. Consider next a fiscal feedback rule correcting at least partially for the unintended deficit shock:

$$
d_{t}=\bar{d}_{t}+\varepsilon_{t}-\gamma \varepsilon_{t-1}
$$

The primary deficit now is subject to shocks, but also contains a feedback reaction whereby a fraction $\gamma$ of the shock in the previous period is offset this period. We furthermore asume that the shock is discovered "late" so that no interest is paid over the shock itself the first undiscovered period). ${ }^{2}$ One could think of bills kept hidden and paid too late. Using the subscript "FR" and "NFR" for cases where there is respectively there is not such a feedback rule, it follows that:

2 See for details Electronic Supplementary Material. 


$$
\begin{aligned}
\operatorname{var}\left(b_{t}^{\tau}\right)_{F R} & =\operatorname{var}\left(\sum_{1}^{\tau} \varepsilon_{t}(1-\gamma)(1+r)^{t^{\prime}-1}\right) \\
& =(1-\gamma)^{2} \sigma^{2} \frac{(1+r)^{2 \tau}-1}{(1+r)^{2}-1} \\
& =(1-\gamma)^{2} \operatorname{var}\left(b_{t}^{\tau}\right)_{N F R}
\end{aligned}
$$

Clearly a fractional offset coefficient $\gamma \subset(0,1)$ leads to variance reduction. Incidentally, Eq. (7) shows that $\gamma \subset(1,2)$ would also lead to variance reduction, but the resulting sawtooth pattern is presumably undesirable. Also, (7) does not depend on $\tau$, so it holds for all finite projection horizons as well as for asymptotic distributions. For the more common timing assumption where deficit shocks and the resulting change in debt increase do lead to immediate interest charges changing correspondingly, the formula for variance reduction is slightly different:

$$
\operatorname{var} b_{t}^{F R}=(1+r-\gamma)^{2} \operatorname{var} b_{t}^{N F R}
$$

Compare the Electronic Supplementary Material for detailed proof. Again we get a time independent proportional reduction in variance. The fact that the reduction coefficient is independent of time also means that even with such a feedback rule, the variance will grow indefinitely and linear in time.

Of possibly more interest is a feedback rule similar to the one proposed in Bohn (2007), where deficits are adjusted to partially correct for deviations of debt from a given target ratio (or target time path). That is in fact the rule we will use in the simulation section below. Such a rule is also closer to for example the requirements of the SGP and would apply the feedback coefficient not to shocks to the deficit of the previous year but to deviations from debt from a previously agreed time path. To save on tedious notation, we assume that the non-stochastic deficit is compatible with the debt target and that time starts with the economy at the target level of debt:

$$
\begin{aligned}
b_{0} & =\bar{b} \\
\bar{d} & =-r \bar{b}
\end{aligned}
$$

The debt feedback rule now becomes:

$$
d_{t}=\bar{d}_{t}+\varepsilon_{t}-\gamma\left(b_{t-1}-\bar{b}\right)
$$

Debt dynamics then become:

$$
\begin{aligned}
b_{1} & =\bar{d}+\varepsilon_{1}+(1+r) b_{0} \\
& =b_{0}+\varepsilon_{1} \\
b_{2} & =\bar{d}+\varepsilon_{2}-\gamma \varepsilon_{1}+(1+r)\left(b_{0}+\varepsilon_{1}\right) \\
& =b_{0}+\varepsilon_{2}+(1+r-\gamma) \varepsilon_{t-1} \\
b_{3} & =\bar{d}+\varepsilon_{3}-\gamma \varepsilon_{2}-\gamma(1+r-\gamma) \varepsilon_{1}+(1+r)\left(b_{0}+\varepsilon_{2}+(1+r-\gamma) \varepsilon_{1}\right)
\end{aligned}
$$




$$
\begin{aligned}
= & b_{0}+\varepsilon_{3}+(1+r-\gamma) \varepsilon_{2}+(1+r-\gamma)^{2} \varepsilon_{1} \\
& \cdot \\
b_{\tau}= & b_{0}+\sum^{\tau}(1+r-\gamma)^{\tau^{\prime}-1} \varepsilon_{\tau^{\prime}} \\
=> & \operatorname{var} b_{\tau}^{F R}=\sigma^{2} \frac{(1+r-\gamma)^{2 \tau}-1}{(1+r-\gamma)^{2}-1} \\
\lim _{\tau \rightarrow \infty} \operatorname{var}\left(b_{\tau}^{F R}\right)= & \frac{\sigma^{2}}{1-(1+r-\gamma)^{2}} \text { for } \gamma>r
\end{aligned}
$$

With this debt feedback rule the elegance of a time independent variance reduction is lost of course. But with a feedback rule tied to reduction of excessive (i.e. above target) debt, the drift towards infinite variance that exists without debt feedback rule will be reversed if at least $\gamma<r$. In the simulation section of the paper we use debt feedback rule (10) with the non-stochastic debt projections as target (time dependent) debt levels.

\section{Data and Estimation Preliminaries}

\subsection{Data}

We obtained time series for Dutch debt, fiscal deficits and average interest rates going back to the Napoleonic times (1814-2009) from Bos (2007) and supplemented it where necessary by official sources. ${ }^{3}$ Bos (2007) obtained the data in his 2007 publication in turn from Statistics Netherlands [CBS 1959, CBS 2001] and from the Dutch economic historian professor J.L. van Zanden and updated his data using the same definitions until 2009. In Fig. 1 we show the evolution of the implied debt output ratio over the entire period.

The debt output ratio shows a highly unusual pattern in the first half of the nineteenth century but corresponds more to modern views on appropriate debt policy afterwards. The ratio incereases rapidly AFTER the end of the Napeolonic wars and French occupation and stays high until about 1845 . From 1845 to 1870 the ratio gradually declines to about one.

Modern views on debt policy would lead one to expect debt to rise during wars but to decline gradually afterwards as the burden of war is shared with future generations. This is the pattern observed around the period of the second world war: immediately after the war the debt/output ratio again exceeds 2, but starts declining immediately, also in about 25 years, this time to around 0,5 . There is once again a rapid build up of debt over the early eighties after which follows a plateau of about a decade. The debt/output ratio starts to decline again from 1994 onwards for about ten to twelve years, coinciding with the long tenure of finance minister Zalm.

3 Statistics Netherlands [CBS 1959, CBS 1994, CBS 2001, http://www.cbs.nl] 


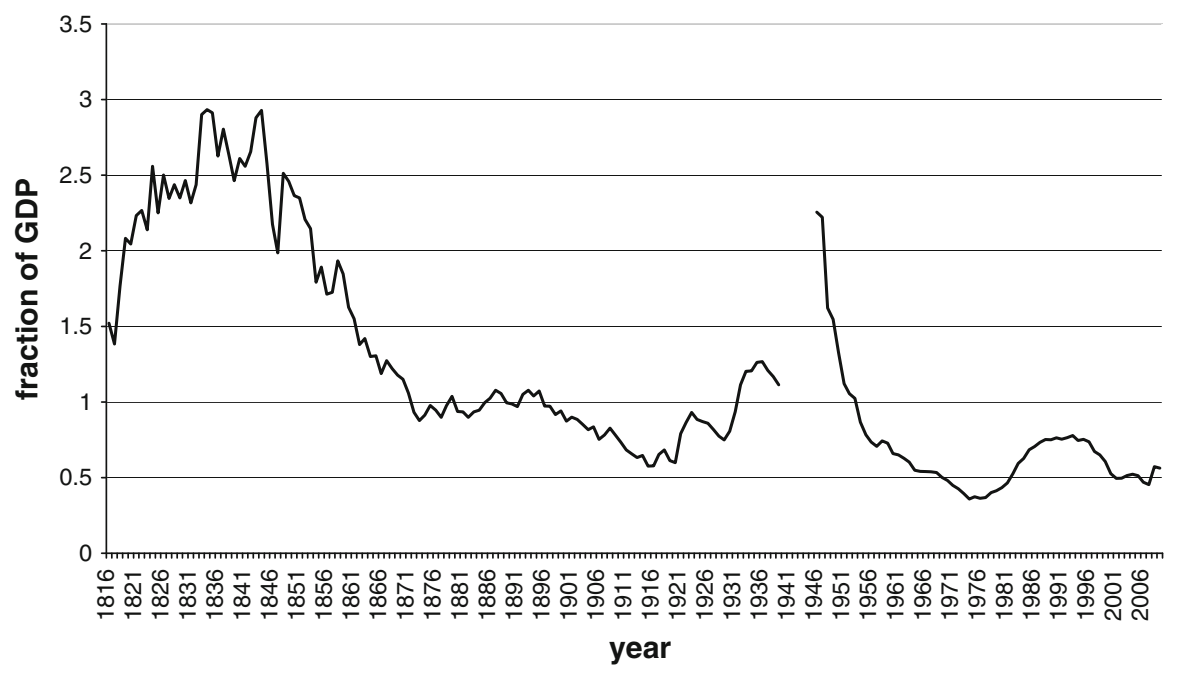

Fig. 1 Debt-to-GDP ratio 1816-1939, 1946-2009

A possible inconsistency in the data can be found in interest expenditure. For the periods 1814-1850 and 1900-1947 we have time series of general and central government debt and central government interest expenditure. We used the assumption that non-central government debt has the same interest rates as central government debt. This assumption is motivated by the fact that in the Netherlands the central government steps in and takes over debts and administrative responsibility if a local government is heading for default. For the period 1851-1899 we have only general government debt and central government interest expenditure. Here we assume central government debt to increase linearly from $74.0 \%$ of general government debt in $1850-79.8 \%$ in 1900 (the endpoints for which we do have complete data) and calculate general government interest expenditure accordingly.

From 1948 onwards we have complete data, for earlier periods various approximations were necessary particularly for interest rates on debt issued by lower levels of Government. Since those debts are guaranteed by the central government, the differences must have been minor. We have tested for robustness by using central instead of general government interest expenditure, but found none of the regression coefficients except for the constant term to change by more than one standard deviation.

From these data we construct the time series used in this paper. Construction and definition of most of these variables is straightforward except for the GDP deflator $(P)$ and Yvar, which we will focus on here. The GDP deflator captures the prices level of GDP. Bos (2007) provides GDP price changes from 1816 to 1913, 1922-1939 and 1949-2009, Statistics Netherlands [http://www.cbs.nl] provides a consumer price index from 1900 to 2008 . CPI is highly correlated with GDP price change in the period 1900-1913, 1922-1939 and 1949-2009. Correlation is 0.998 on level and 0.949 on first differences. We therefore approximate GDP price changes from 1914 to 1921 and from 1940 to 1948 by corresponding changes in the CPI and obtain in this way the GDP deflator for the entire period 1815-2009. 
We capture the cyclical component in GDP by splitting the logarithm of real GDP in a trend and a cyclical component using a Hodrick-Prescott filter with lambda = 100 (standard setting for annual data). The cyclical component seems to capture the business cycle reasonably well: it is negative during a crisis (1933, early 1980, 2002, $2009)$ and positive during booms $(1929,1999,2007)$. This is a very straightforward way to capture the cyclical component of GDP or proxy the output gap. A more sophisticated way is to estimate potential GDP and examine the difference between actual and potential GDP (see [OECD 2005]). Our method however generates comparable results. The OECD examines the impact of regressing their output gap on the primary surplus for the period after 1972 and obtains a value of 0.55 . If we regress yvar on the primary surplus in this period we obtain 0.52 with a standard deviation of 0.16 , which seems reasonably close to the OECD results.

\subsection{Estimation Preliminaries: Data Analysis}

Before we can start estimating the value of the debt feedback coefficient in the time series model for the primary deficit series (Eq. (4)), we have to address the possible presence of a unit root, to check whether OLS can be used without picking up spurious correlation. In Table 1 a Dickey-Fuller test has been performed for different time periods, with both AIC and SIC selection criteria on the series $d_{t}, b_{t}$ and $\Delta b_{t}$, with the variables $d_{t}, b_{t}$ defined as ratios to GDP. The presence of a unit root in the primary deficit is rejected for all time periods and all selection criteria at the $10 \%$ significance level. Most tests are also significant at the $5 \%$ level, except for the ADF using AIC for the period 1814-2009, which is borderline significant. Hence we presume that the primary deficit series is stationary.

The debt series, however, show a different story. The first difference series seems to be stationary, but in levels the results are more ambiguous. For the post-war period, 1949-1990, the presence of a unit root is strongly rejected. For the period 1991-2009, the tests fail to reject the null hypothesis, but this could well be due to a lack of power, since there are only 18 data points. When considering the sample period 1949-2009, the ADF test using AIC does not reject the null hypothesis, but the ADF test using SIC is highly significant. However, for the period 1814-1939, we get the reverse results, with

Table 1 ADF unit root tests on primary deficit and debt as a percentage of GDP

\begin{tabular}{|c|c|c|c|c|c|c|}
\hline Variable & Test used & 1814-2009 & 1814-1939 & 1949-2009 & 1949-1990 & 1991-2009 \\
\hline \multirow[t]{2}{*}{$d_{t}$} & $\begin{array}{l}\mathrm{ADF} \text {-intercept, AIC selection } \\
(p \text { value })\end{array}$ & 0.07 & 0.04 & 0.00 & 0.00 & 0.03 \\
\hline & $\begin{array}{l}\mathrm{ADF} \text {-intercept, SIC selection } \\
(p \text { value })\end{array}$ & 0.00 & 0.04 & 0.00 & 0.00 & 0.03 \\
\hline \multirow[t]{2}{*}{$b_{t}$} & $\begin{array}{l}\mathrm{ADF} \text {-intercept, } \mathrm{AIC} \text { selection } \\
(p \text { value })\end{array}$ & 0.11 & 0.06 & 0.27 & 0.00 & 0.65 \\
\hline & $\begin{array}{l}\text { ADF_-intercept, SIC selection } \\
\text { ( } p \text { value })\end{array}$ & 0.49 & 0.73 & 0.00 & 0.00 & 0.65 \\
\hline \multirow[t]{2}{*}{$\Delta\left(b_{t}\right)$} & ADF-AIC selection ( $p$ value) & 0.00 & 0.05 & 0.00 & 0.00 & 0.00 \\
\hline & ADF-SIC selection ( $p$ value) & 0.00 & 0.00 & 0.00 & 0.00 & 0.00 \\
\hline
\end{tabular}


Table 2 Dependent variable: primary deficit

Sample ranging from 1814 to 2009, breakpoint in 1991

\begin{tabular}{lclll}
\hline Variable & Coefficient & SE & $t$-Statistic & Prob. \\
\hline$C$ & 0.638 & 0.264 & 2.42 & 0.0166 \\
PD $(-1)$ & 0.702 & 0.043 & 16.4 & 0.0000 \\
DEBT $(-1)$ & -0.011 & 0.002 & 4.73 & 0.0000 \\
YVAR & -0.019 & 0.040 & 0.46 & 0.6469 \\
BREAK $\times$ PD $(-1)$ & -0.836 & 0.216 & 3.87 & 0.0002 \\
BREAK $\times$ DEBT $(-1)$ & -0.042 & 0.010 & 4.12 & 0.0001 \\
BREAK $\times$ YVAR & -0.872 & 0.256 & 3.41 & 0.0008 \\
$R^{2}$ & 0.777 & \multicolumn{3}{l}{ BG $(2)$} \\
BP & 0.534 & RESET(2) & 0.494 \\
\hline
\end{tabular}

the AIC rejecting the presence of a unit root at the $10 \%$ significance level, while the SIC does not reject. For the full sample neither test indicates that debt levels are stationary.

These ambiguous results make it difficult to conclude whether debt series are stationary or not on the basis of the test results alone. One possible explanation why the $\mathrm{ADF}$ tests in some cases fail to reject the presence of a unit root could be a serious lack of power. It can be shown that, if one assumes that debt levels are stationary, the coefficient in the ADF test equation will be very close to unity, hence it would require a large amount of observations to distinguish between this coefficient and a coefficient equal to unity. Whether this coefficient lies close to unity depends among others on the size of the debt feedback and the coefficient of the lagged primary surplus. We find that for the full sample the Dickey-Fuller test coefficient lies very close to unity. Since some of the tests do (strongly) reject the presence of a unit root and we have shown why a Dickey-Fuller test is likely to be particularly particularly weak in this case, we will assume that the debt-to-gdp ratio time series are also stationary. ${ }^{4}$ Hence in the next section we will estimate Eq. (4) with OLS.

\section{Results: Estimating the Feedback (Cointegration) Coefficient}

The estimates of model (4) are shown in Table 2. We added the outputgap (as a percentage of GDP) to the equation to capture cyclical fluctuations in the primary surplus. A number of misspecification tests have been performed to assess the validity of model. The Breusch-Godfrey and the Breusch-Pagan tests have been performed to test for the possible presence of autocorrelation and heteroscedasticity respectively. Detection could indicate that our model is misspecified, and that estimated standard errors are biased. But neither test rejects the null hypothesis of no autocorrelation and no heteroscedasticity even at the $10 \%$ significance level. The tests in Table 2 are carried out with two lags, but we find similar results with one and three lags. To test for possible

\footnotetext{
4 The referee has pointed out that, since the series is expressed as a percentage of GDP, non-stationarity may also not be rejected because, of the pattern in GDP.
} 


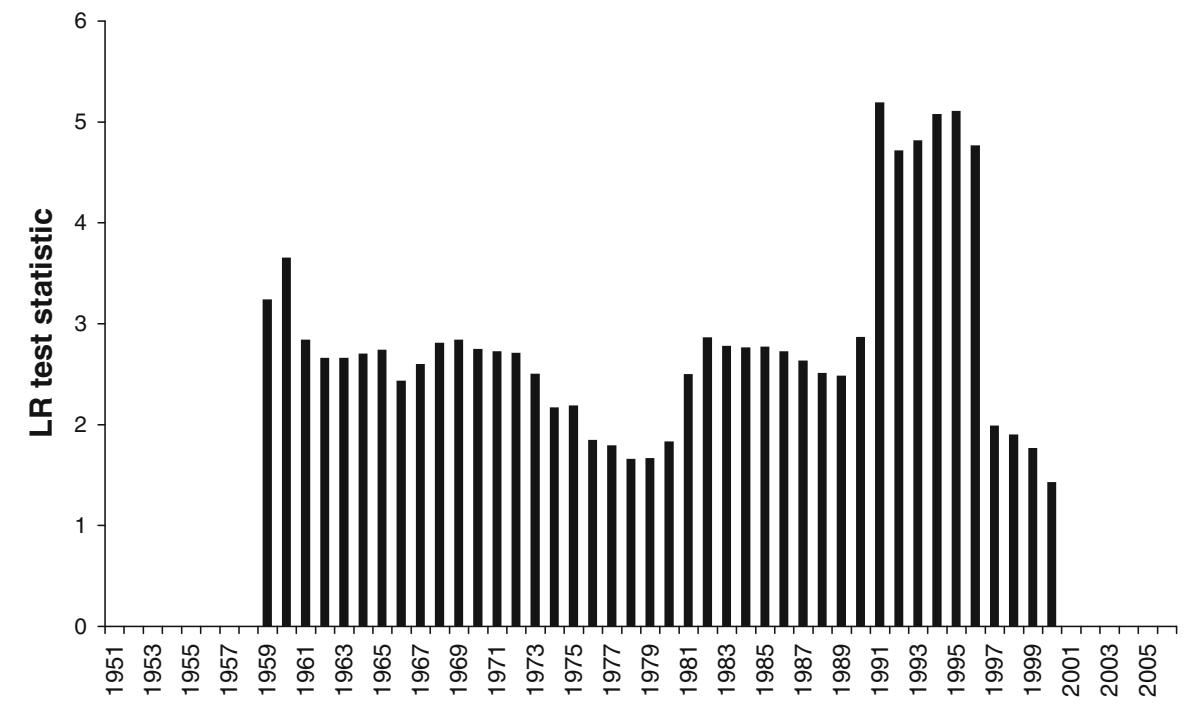

Fig. 2 LR test statistic for a breakpoint with given year as breakpoint. Regression performed on the subsample 1949-2009

nonlinearities, we perform a RESET test with two lags. Also this test finds no evidence that our model is misspecified.

Preliminary tests ${ }^{5}$ showed that the size of the feedback coefficient changes a lot over different subsamples, so we checked for a structural break in the post-war period. To examine this, we perform a Quandt-Andrews breakpoint test on the 1814-1939 subsample and on the 1949-2009 sub sample with 15\% trimmed data. for each given year and the year on the $x$ axis modeled as the breakpoint year.

For the 1814-1939 subsample the most likely location for a breakpoint is 1,848 , with LR test statistic 2.95 (see Fig. 2). The $p$ value of this statistic is 0.224 and we therefore fail to reject the null hypothesis of no breakpoints. For the 1949-2009 subsample we find the most likely location for a breakpoint to be 1991, with LR test statistic of 5.18. The $p$ value of this statistic is 0.009 and we therefore do reject the null hypothesis of no breakpoints in this sub period. In Fig. 2 the LR-statistic used in the Quandt-Andrews breakpoint test is depicted corresponding with a breakpoint test. Assuming 1991 is a breakpoint, we test for a second break in the sub sample 1949-2009, again using the Quandt-Andrews breakpoint test.

We find that the most likely location for an additional breakpoint would be 1960, but with a LR test statistic of 2.18. The $p$ value of this statistic is 0.520 and we therefore fail to reject the null hypothesis of only one breakpoint. When using the entire sample 1814-2009 to search for structural breaks in the data, we again find one structural break in 1991 and, after adding this structural break to the regression, fail to reject the null hypothesis of no additional structural break. We thus conclude that there is only one structural breakpoint in the data (1991). To incorporate this structural break, the model

5 Available on request from the first author. 
is augmented with a time dummy $B R E A K$, which is equal to unity for all years from 1991 onwards and zero for all earlier years. The dummy premultiplies the "behavioral" parameters as a test for a change in policies. The results are reported in Table 2.

The coefficient of particular interest, the feedback coefficient, is the one corresponding to DEBT(-1) in Table 2. For the years prior to 1991, the feedback coefficient, $\beta=0.01$, is small in magnitude but significantly negative. After 1991 the feedback coefficient jumps from -0.01 to $-0.05(=-0.01$ to 0.04$)$ ), and the increase is again highly significant. These results confirm the hypothesis that the Dutch government reduces its primary deficit whenever debt levels are rising. The 1991 jump in the feedback coefficient may be related to the Dutch plans to join the (then future) Euro, which required compliance with the $\mathrm{SGP}^{6}$ and EMU criteria regarding maximum debt levels and fiscal deficits. The treaty of Maastricht in which the debt and deficit criteria were embedded, was (pre-)negotiated in 1991 and signed February 7, 1992. After the rapid run up of debt in the eighties, fiscal policy was indeed substantially tightened by finance ministers Kok (1991-1994) and Zalm (1994-2004)).

In 1991 not only the attitude towards public debt changed, a shift can also be observed in the other two explanatory variables of the primary deficit. Before 1991, last years' primary deficit, which has a regression coefficient of 0.702 , was more or less carried over to the current year. From 1991 onwards however, persistence goes down substantially, last years' budget loses its relevance for this years' budget, with an insignificant combined coefficient of $-0.133(=+0.702-0.836) .1991$ was also a breakyear for anti-cyclical policy. Before 1991 the coefficient on yvar is statistically indistinguishable from 0, but from 1991 onwards, the variable becomes highly significant and has value 0.891 . These two shifts togethercan be interpreted as a switch to a more structural trend-based fiscal policy, which was in fact formalized as a budget rule (“Zalm norm") in 1994.

\section{Stochastic Debt Projections}

In the previous section the debt feedback coefficient was estimated for different time periods. Theory predicts that a positive feedback coefficient ensures that debt is sustainable. To show the impact of such a feedback coefficient on the distribution of future debt stocks, we simulate the future distribution of debt levels under different scenarios. We obtain annual projections for the output gap, long-term interest rate and nominal GDP growth rate from the OECD Economic Outlook no. 87, preliminary edition (OECD 2010). We use OECD projections as a baseline because this allows for simple international comparison. Forecasts are made from 2010 to 2040. Unfortunately, OECD projections are only available till 2018. For subsequent years we assumed interest rates to be constant and set the output gap to zero.

We use an appropriately adjusted version of the feedback rule from Eq. (10) using the estimation results from Table 2. The simulation model then becomes:

6 Stability and Growth Pact. 


$$
\begin{aligned}
\text { (a) }: d_{t} & =\left(1+i_{t}-\gamma_{t}\right) d_{t-1}+p d_{t} \\
\text { (b) }: p d_{t} & =\alpha_{1}+\alpha_{2} p d_{t-1}+\alpha_{3} d_{t-1}^{b}+\alpha_{3}\left(d_{t-1}-d_{t-1}^{b}\right)+\alpha_{4} \operatorname{yvar}_{t}
\end{aligned}
$$

where $i_{t}$ is the nominal interest rate, $\gamma_{t}$ is nominal GDP growth and yvar ${ }_{t}$ is the output gap. The output gap is defined as the deviation of actual GDP from potential GDP (OECD definition) as a percentage of potential GDP. $i_{t}, \gamma_{t}$ and yvar ${ }_{t}$ are the stochastic exogenous variables, which are obtained by complementing the OECD projections with a random vector $\varepsilon$, i.e.:

$$
\left(\begin{array}{l}
i_{t} \\
\gamma_{t} \\
\operatorname{yvar}_{t}
\end{array}\right)=\left(\begin{array}{l}
i_{t}^{b} \\
\gamma_{t}^{b} \\
\operatorname{yvar}_{t}^{b}
\end{array}\right)+\left(\begin{array}{l}
\varepsilon_{t}^{i} \\
\varepsilon_{t}^{\gamma} \\
\varepsilon_{t}^{\mathrm{yvar}}
\end{array}\right)
$$

The random vector $\varepsilon_{t}$ is drawn for each period independently, but we do allow for contemporaneous correlation between the individual elements. We assume that the vector with nominal interest rates, nominal GDP growth and the output gap follows a VAR process. We tested for the possible number of lags and found that most criteria identified two lags as the best fit, hence we specified the following model:

$$
\left(\begin{array}{l}
i_{t} \\
\gamma_{t} \\
\operatorname{yvar}_{t}
\end{array}\right)=C+A_{1}\left(\begin{array}{l}
i_{t-1} \\
\gamma_{t-1} \\
\operatorname{yvar}_{t-1}
\end{array}\right)+A_{2}\left(\begin{array}{l}
i_{t-2} \\
\gamma_{t-2} \\
\operatorname{yvar}_{t-2}
\end{array}\right)+\varepsilon_{t}, \operatorname{Var}\left(\varepsilon_{t}\right)=\Sigma
$$

To obtain an estimate of $\Sigma$, we estimate model (14) and use the residual covariance matrix $\hat{\Sigma}$.

The superscript $b$ in Eq. (13) stands for baseline and refers to either the nonrandom projections obtained from the OECD or the nonrandom endogenous variables $p d_{t}^{b}$ and $d_{t}^{b}$, which are obtained by iterating model (12) with the nonrandom projections as input variables. The fourth term in (12) $b$ naturally cancels out in generating baseline projections. The fourth term in model (12) $b$ ensures that the primary deficit is lowered whenever debt levels exceed the baseline debt level by a fraction of the difference. This way the distribution will be centered around the projected baseline debt level. Figure 3 shows the first simulation results, for simulations without feedback coefficient.

In Fig. 3 the debt feedback coefficient is set to zero. The upper graph shows 95 and $90 \%$ confidence intervals (CI). It is clear that there is a significant possibility debt will stay high for the indefinite future. The lower graph depicts the probability that debt levels will exceed 65, 70 and 70\% of GDP respectively, for any given year, which we loosely define as crisis probabilities, the probability that in a given year the debt-to-output ratio will exceed critical values (cf Reinhart et al. 2003). Taking $65 \%$ as a benchmark value, that probability is quite high for the coming years, which reflects the increases in government debt over the crisis period 2008-2010. After 2014 the probability declines gradually.

Now compare Figs. 3 and 4. In the latter the debt feedback coefficient is set to 0.0525 , the estimate obtained in Table 2. One can clearly see that this distribution is much more narrow, as predicted by our result from Eq. (7). Moreover, though the 

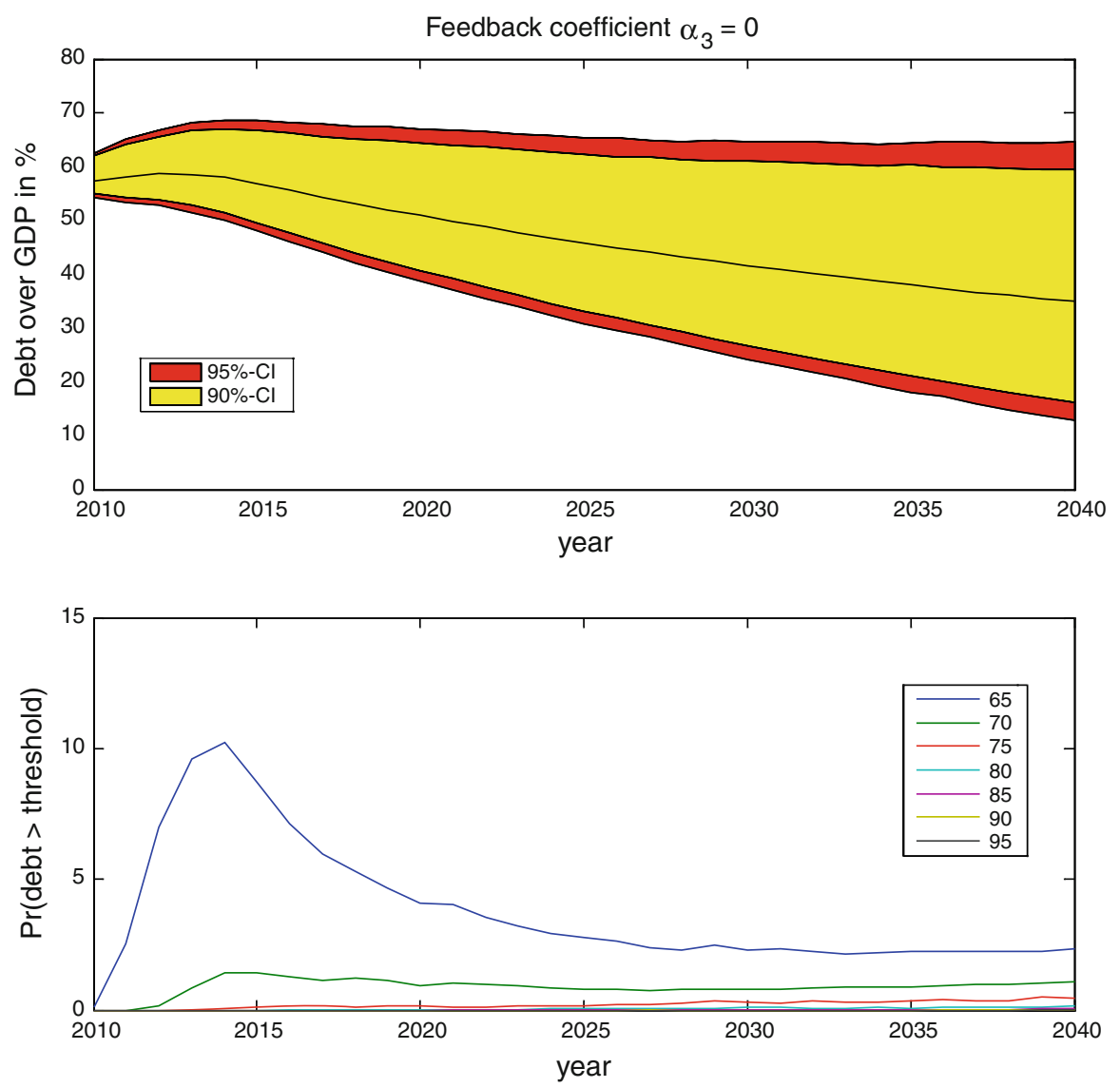

Fig. 3 Estimates from 1991 to 2009 sample and primary surplus treated endogenously

probability that debt levels will exceed $65 \%$ of GDP in the near future is similar to the one with no feedback, in the longer run this probability is much smaller. Stability will be enhanced correspondingly.

A disadvantage of the simulations performed sofar is that they deviate in one important aspect from the way governments and organizations like the OECD or the IMF perform them. Those organizations typically make deterministic debt projections based on a particular assumption (time path) for the primary deficit/surplus as a ratio to GDP. Because of our assumption of a fully endogenous primary deficit, our central line (expected future debt stocks) deviates significantly from the determinist simulations performed more commonly, which, as said, are typically based on the assumption of a fixed ratio between the primary deficit and GDP. That makes the projections difficult to compare.

We therefore produce a second set of simulations, set up in such a way that the baseline (timepath of expected future debt/output ratios, the central black line in the figures) is comparable to the deterministic projections typically made. For the second 

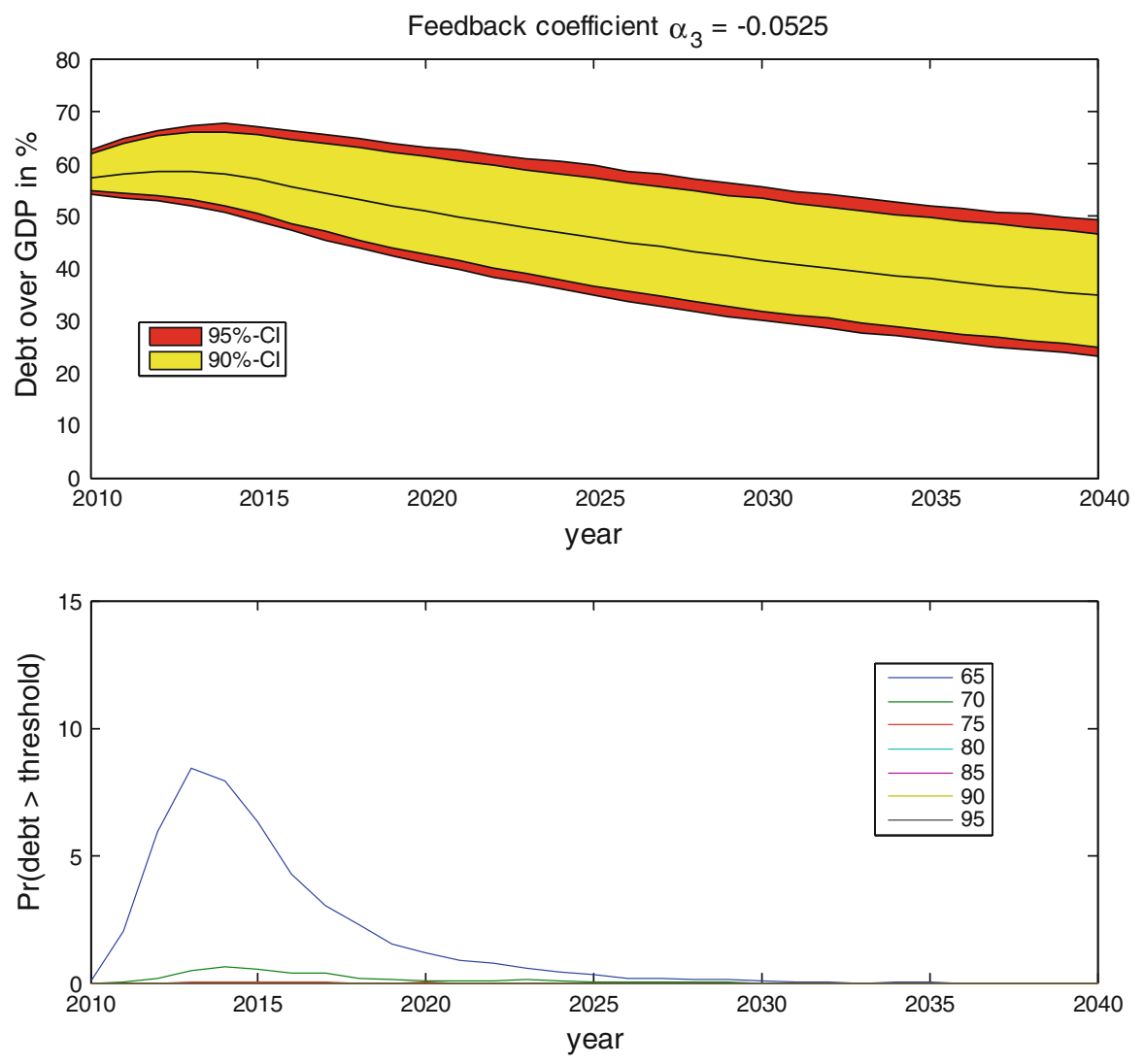

Fig. 4 Estimates from 1991 to 2009 sample, primary surplus treated endogenously, active feedback coefficient

set of stochastic simulation we take the core primary deficit as exogenous and project a baselevel path for the debt/output ratio based on deterministic debt dynamics, exactly in the way such projections are usually set up. We base this central target line on OECD projections for the primary deficit in the Netherlands. Then we add shocks, and deficits are allowed to respond (deviate from their core value) with the estimated feedback coefficient to deviations from the target time path for debt. This is very similar to the rule now discussed in the European context for the new Stability Pact.

Formally, the set up now is (with the same definitions of variables and a superscript " $b$ " indicating the deterministic baseline values):

$$
\begin{aligned}
d_{t} & =\left(1+i_{t}-\gamma_{t}\right) d_{t-1}+p d_{t} \\
p d_{t} & =\alpha_{1}+\alpha_{2} p d_{t-1}^{b}+\alpha_{3}\left(d_{t-1}-d_{t-1}^{b}\right)
\end{aligned}
$$

Since the OECD only has projections of primary deficits/surpluses from 2010 to 2016, we set a primary surplus constant at $1.1 \%$ of GDP for all subsequent years 

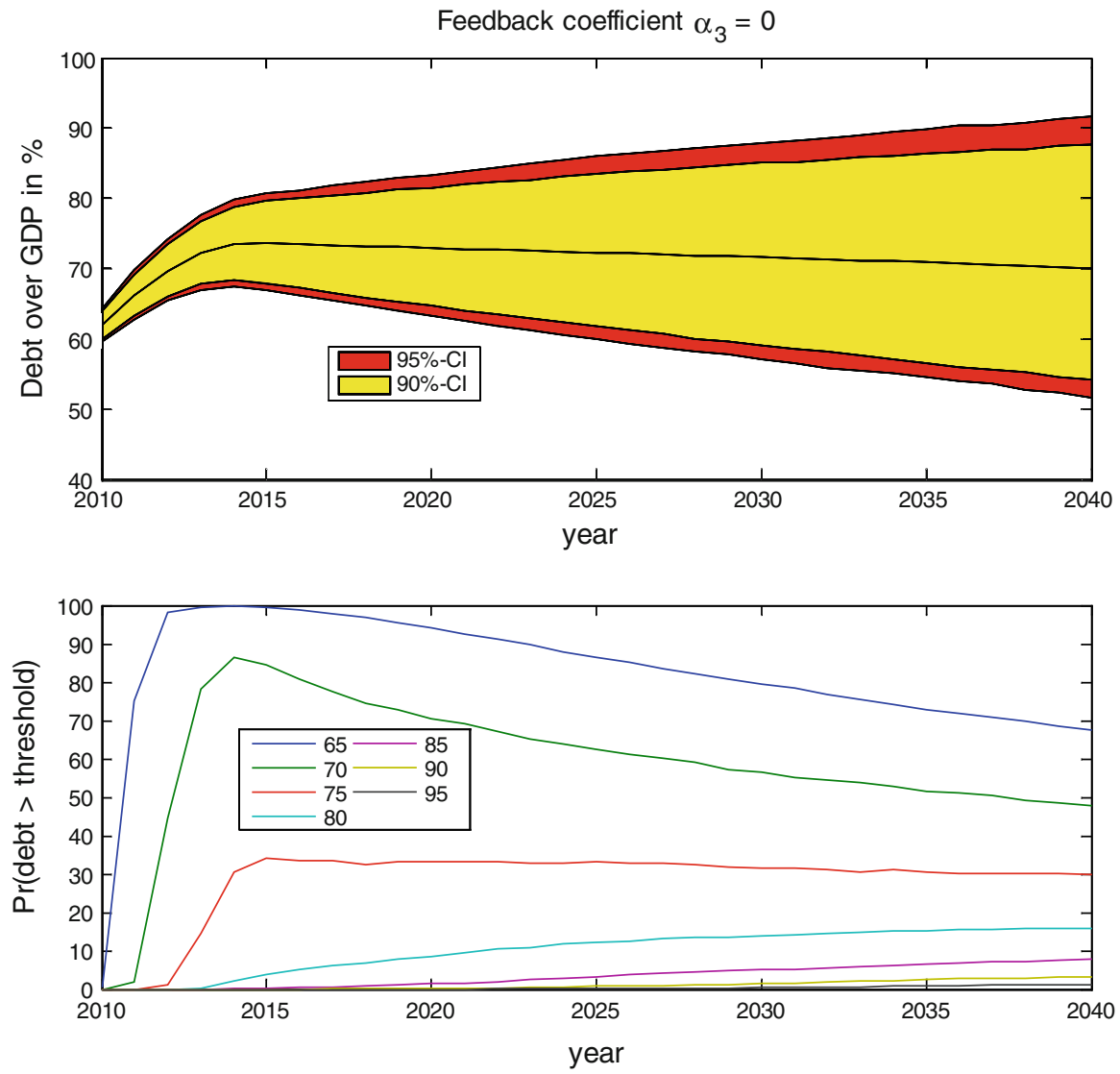

Fig. 5 Estimates from 1991 to 2009 sample and primary surplus treated exogenously

(deficit equal to $-1.1 \%$ of GDP), in line with the OECD projection for 2016 . The fact that the baseline debt level declines less fast than in the previous simulation is due to the relatively low and constant primary surplus compared to the outcome of our simulation with the econometrically estimated deficit equation. The results are shown in Fig. 5 (zero feedback coefficient) and 6 (empirically estimated feedbck coefficient) (Fig. 6).

Just like in the previous simulation, the distribution of debt levels is much wider when there is no feedback coefficient. In 2040 the $95 \%$ confidence interval of the distribution covers a range from 50 to $90 \%$ of GDP, while with a debt feedback coefficient, a range of only $60-80 \%$ is covered, half the width.

The behavior of the crisis probabilities shows an interesting pattern. Contrary to the earlier two simulations we do not see a strong across the board decline in spite of the narrowing of the distribution as time goes by. Only for the critical levels that are well above the central time path associated with the non-stochastic OECD projections show decline, and the more so the further they are above it. 

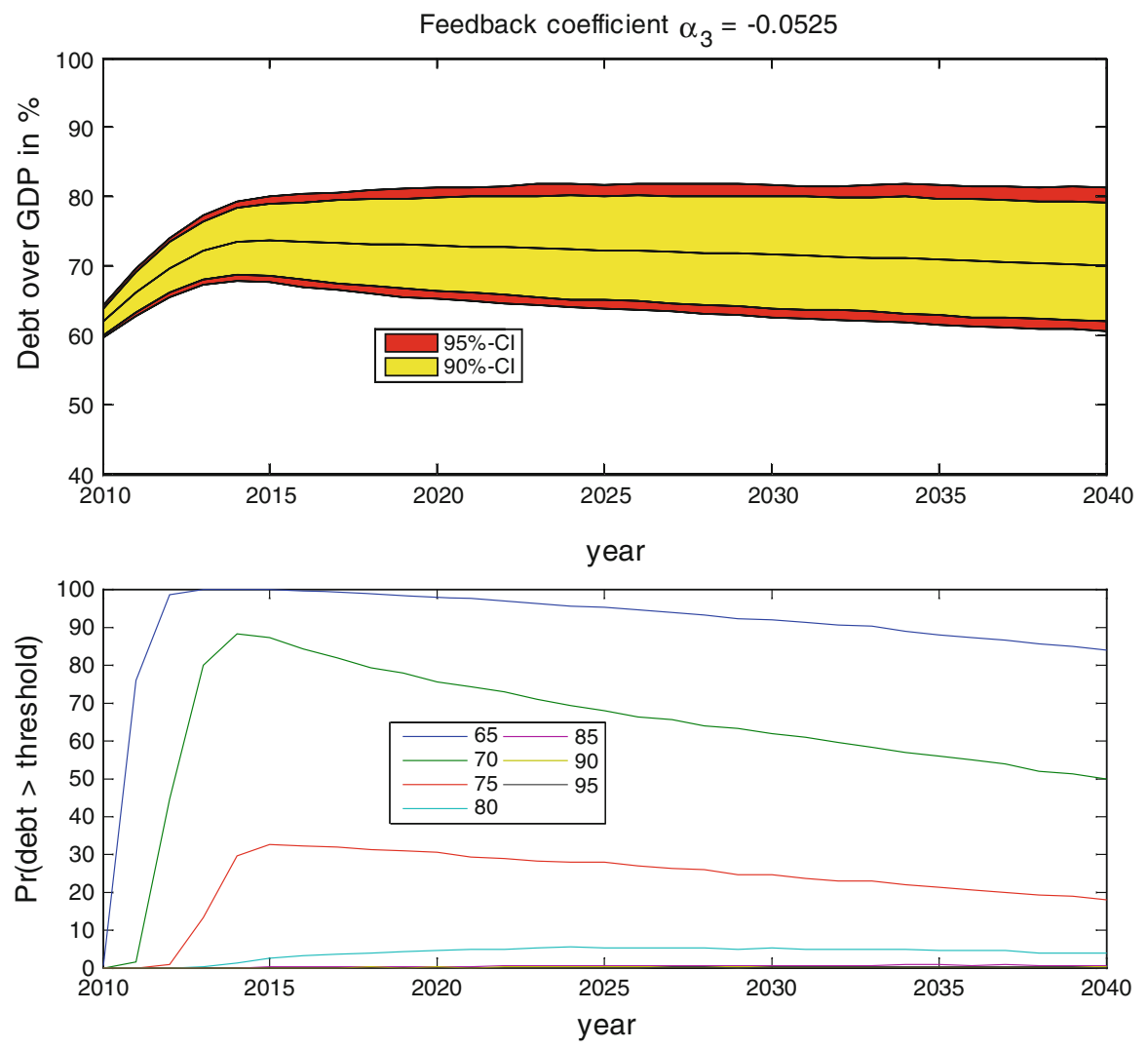

Fig. 6 Estimates from 1991 to 2009 sample and primary deficit treated exogenously (except for feedback coefficient)

The explanation of this pattern should be clear: consider the extreme case where the central path would equal a particular critical value; in that case narrowing the distribution would have no impact on the crisis probabilities at all, they would remain at $50 \%$ for any variance. And if the central path is above the critical value, narrowing the distribution will actually increase the crisis probabilities: it then becomes more certain that the debt-to-output ratio will exceed the critical level as time goes by and as the distribution narrows down towards a time path that itself exceeds the critical value. Only if the central time path itself is significantly below the critical value used, will a narrowing of the distribution around the central path actually reduce crisis probabilities.

\section{Conclusions}

The Greek debt crisis of 2010/2011 has brought the issue of fiscal sustainability back into the policy debate. Existing theory has mostly focused on satisfying terminal value conditions essentially coming down to the restriction that debt levels should 
eventually grow at less than the rate of interest. The applied literature has made the obvious step towards a stochastic framework by equating fiscal sustainability with rejection of unit roots in tests applied to time series of debt stocks, or, equivalently, requiring difference stationarity. However in a powerful recent paper, Bohn (2007) has demonstrated that difference stationarity of any finite order is consistent with satisfaction of the Intertemporal Budget Constraint (ITBC) and suggests alternative approaches focusing on the presence of Error Correction Mechanisms in the debt/deficit processes. Is the country under consideration sufficiently responsive to rising debt levels?

There is also a more economic and less statistical approach to the problem pointing at the likelihood that when debt levels rise and approach critical levels, tax payers may revolt against the associated debtservice burden (Schabert and van Wijnbergen 2006, 2010; Davig et al. 2011). Equivalently, funding problems may arise in capital markets when lenders start anticipating such revolts and refuse participation in debt auctions (Reinhart et al. 2003). In this paper, we provide a stochastic framework to assess whether such problems may arise, and in particular, whether critical debt levels will be exceeded. We combine this stochastic simulation approach with an analysis based on the view expressed in Bohn (2007), arguing that the key to fiscal sustainability in a stochastic environment is a feedback rule from debt level shocks back to corresponding adjustments in the primary surplus process. We show formally, and demonstrate in our simulation analysis empirically, that such feedback rules through which debt surprises are (partially) corrected by offsetting changes in the primary surplus, narrow future distributions of debt-output ratios and so reduce crisis probabilities. We apply the methodology to Dutch debt and deficit data spanning two centuries.

The empirical analysis clearly shows that according to the Bohn criterion, Dutch deficit/debt processes have throughout two centuries satisfied sustainability criteria, with more active policies pursued postwar than pre-war. Moreover fiscal policy seems to have been tightened substantially since the labor party's finance minister Wim Kok took over in 1991 and the Netherlands actively took part in the negotiations that eventually led to the Euro. Prior to 1991, the business cycle was not an important factor determining Dutch fiscal policy outcomes. But from 1991 onwards, boom periods reduced primary deficits and downturns led to larger deficits, suggesting a shift towards a more structural trend-based fiscal policy.

We then used these econometric results together with simulation methods to assess empirically the impact of feedback rules on the variance of future debt distributions. The simulation results confirm the theoretical results of the first section of the paper on the strong reduction in variance of future debt distributions under the adoption of fiscal feedback rules as promoted by Bohn (2007). We introduce a new measure of collapse probability, i.e. the probability that in any given future year critical debt levels will be exceeded and show how Bohn-like fiscal feedback rules strongly diminish such crisis probabilities if at least the non-stochastic projections remain below those critical levels. Our results strongly argue for the incorporation into any revised Stability pact of Bohn-type fiscal feedback rules, rules stipulating tightening fiscal policy whenever debt stocks exceed previously agreed upon targets. 
Acknowledgments Sweder van Wijnbergen and Alexander France are indebted to the Netherlands Bureau of Policy Analysis (CPB) for providing access to sources and to Jasper Lukkesen (CPB) for research assistance.

Open Access This article is distributed under the terms of the Creative Commons Attribution License which permits any use, distribution, and reproduction in any medium, provided the original author(s) and the source are credited.

\section{References}

Bohn, H. (2007). Are stationarity and cointegration restrictions really necessary for the intertemporal budget constraint?. Journal of Monetary Economics, 54, 1837-1847.

Bos, F. (2007). The Dutch fiscal framework: History, current practice and the role of the CPB, CPB document no. 150.

Davig, T., Leeper, E., \& Walker, T. (2011). Inflation and the fiscal limit. European Economic Review, 55-1, 31-47.

Organisation for Economic Cooperation and Development (OECD) (2010). World economic outlook no. 87, Paris.

Reinhart, C., Rogoff, K., \& Savastano, M. (2003). Debt intolerance. BPEA, 2003(1), 1-62.

Schabert, A., \& van Wijnbergen, S. (2006). Debts, deficits and destabilizing monetary policy in open economies, CEPR discussion paper no 5590.

Schabert, A., \& van Wijnbergen, S. (2010). Sovereign default and the stability of inflation targeting regimes, Tinbergen Institute working paper no. TI 11-064.

Trehan, B., \& Walsh, C. (1991). Testing intertemporal budget constraints: Theory and applications to US federal budget and current account deficits. Journal of Money, Credit and Banking, 23(2), 206-233. 